\title{
General Linear Models for Pain Prediction in Knee Osteoarthritis: Data from the Osteoarthritis Initiative
}

\section{Modelos Lineales Generales para Predecir Dolor en Osteoartritis de Rodilla: Datos de la "Osteoarthritis Initiative"}

\author{
J. I. Galván-Tejada', J. G. Arceo-Olague', H. Luna-García', H. Gamboa-Rosales', J. M. Celaya-Padilla², \\ L. A. Zanella-Calzada3, R. Magallanes-Quintanar', C. E Galván-Tejada' \\ 'ClIAM, Unidad Académica de Ingeniería Eléctrica, Universidad Autónoma de Zacatecas \\ ²CONACyT, Universidad Autónoma de Zacatecas \\ ${ }^{3} \mathrm{MACI}$, Unidad Académica de Ingeniería Eléctrica, Universidad Autónoma de Zacatecas
}

\begin{abstract}
Knee pain is the most common and disabling symptom in Osteoarthritis (OA). Joint pain is a late manifestation of the OA. In earlier stages of the disease changes in joint structures are shown. Also, formation of bony osteophytes, cartilage degradation, and joint space reduction which are some of the most common, among others. The main goal of this study is to associate radiological features with the joint pain symptom. Univariate and multivariate studies were performed using Bioinformatics tools to determine the relationship of future pain with early radiological evidence of the disease. All data was retrieved from the Osteoarthritis Initiative repository (OAI). A case-control study was done using available data from participants in OAI database. Radiological data was assessed with different OAI radiology groups. We have used quantitative and semi-quantitative scores to measure two different relations between radiological data in three different time points. The goal was to track the appearance and prevalence of pain as a symptom. All predictive models were statistically significant $(P \leq 0,05)$, obtaining the receiving operating characteristic (ROC) curves with their respective area under the curves (AUC) of $0.6516,0.6174$, and 0.6737 for T-0, T-1 and T-2 in quantitative analysis. For semi-quantitative an AUC of $0.6865,0.6486$, and 0.6406 for T-0, T-1 and T-2. The models obtained in the Bioinformatics study suggest that early joint structure changes can be associated with future joint pain. An image based biomarker that could predict future pain, measured in early OA stages, could become a useful tool to improve the quality of life of people dealing OA.
\end{abstract}

KEYWORDS: linear stochastic models; osteoarthritis; knee pain prediction; cross-sectional studies; radiological biomarkers. 


\section{RESUMEN}

El dolor de rodilla es el síntoma más común y limitante de la Osteoartritis (OA), además de presentarse como una manifestación tardía de la enfermedad. Los cambios que ocurren en las estructuras de las articulaciones se presentan en las primeras etapas de la OA. Algunos de los cambios más comunes son la formación de osteofitos óseos, degradación del cartílago, y la reducción del espacio en la articulación, entre otros. El principal objetivo de este estudio es la asociación de características radiológicas con el síntoma de dolor de las articulaciones, para lo que fueron realizados dos estudios: univariado y multivariado, usando herramientas bioinformáticas para determinar la relación de futuro dolor con la evidencia radiológica temprana de la enfermedad. Todos los datos fueron recuperados de la Osteoarthritis Initiative repository (OAI). Este estudio de caso-control se llevó a cabo utilizando los datos disponibles de los participantes de la base de datos de la OAI. Los datos radiológicos fueron evaluados con diferentes grupos de radiología de la OAI. Fueron usadas puntuaciones cuantitativas y semicuantitativas para medir las dos diferentes relaciones entre los datos radiológicos en tres diferentes puntos de tiempo. El objetivo fue seguir la trayectoria de la aparición y prevalencia del dolor como síntoma. Todos los modelos predictivos fueron estadísticamente significativos $(P \leq 0,05)$. Para el análisis cuantitativo se calcularon las áreas bajo la curva (AUC): 0.6516, 0.6174, y 0.6737 para T-0, T-1 y T-2, y para el análisis semicuantitativo se calcularon las AUC: 0.6865, 0.6486, y 0.6406 para T-0, T-1 y T-2. Los modelos obtenidos en el estudio bioinformático sugieren que los cambios tempranos en la estructura de las articulaciones pueden estar asociados con el futuro dolor de rodilla. Un biomarcador basado en imágenes que pueda predecir el futuro dolor, medido en las primeras etapas de OA, podría convertirse en una herramienta útil para mejorar la calidad de vida de la gente que padece OA.

PALABRAS CLAVE: modelo lineal; osteoartritis; dolor de rodilla; predicción de dolor, estudios transversales, modelos estocásticos, biomarcadores radiológicos.

\section{Correspondencia}

DESTINATARIO: Carlos E. Galván-Tejada

INSTITUCIÓN: CIIAM, Unidad Académica de Ingeniería

Eléctrica, Universidad Autónoma de Zacatecas

DIRECCIÓN: Jardín Juárez \#147, Centro Histórico, C. P.

98000, Zacatecas, Zacatecas, México

CORREO ELECTRÓNICO: ericgalvan@uaz.edu.mx

\section{Fecha de recepción:}

6 de julio de 2017

Fecha de aceptación:

9 de noviembre de 2017 


\section{INTRODUCTION}

Osteoarthritis (OA) is a high incidence disease that brings poor quality of life of many people in the industrialized world. Pain is the most common and incapacitating symptom of knee OA ${ }^{[1-3]}$, this disease affects more than 1 in 10 adults over 60 years only in the United States ${ }^{[4]}$, is one most common form of arthritis in the industrialized world, the lifestyle and age of the general population are factors of an increment in the knee OA cases ${ }^{[5-8]}$. OA remains still poorly understood ${ }^{\text {[9] }}$. For a better study and understanding of pain etiology, the Osteoarthritis Initiative (OAI) has been recollecting thousands of clinical data (features) in OA patients; all these features bring important information about the stages of the pain, and other subject characteristics. In order to diagnose OA, medical imaging is a very important tool, is the most common first hand information, using different radiological techniques as Magnetic Resonance Imaging (MRI) or X-ray imaging, it is possible to obtain a good approach of the OA stage ${ }^{[10]}$. Some literature ${ }^{[11-13]}$, suggest that it is possible to obtain better results using MRI than $X$-ray imaging, this is because the nature of the image itself. Nevertheless, there are others based on both, X-ray and MRI [5, 14-16], and taking advantage of the features obtained from each kind of images.

It is important to take into account that in emerging countries the first approach to diagnose knee OA is $X^{-}$ ray imaging, in early stages of OA the use of MRI images in an exploratory stage is not allowed by the monetary cost to the public health systems, or the patient itself. This is an important reason to develop a robust diagnostic method based on a very extended imaging tool, the $X$-ray imaging technology.

Since Kellgren and Lawrence (K\&L) introduced their assessment scale of knee $\mathrm{OA}^{[17]}$. This has been adopted as a standard in many health systems and OA studies around the world. Over the years, there have been some similar approaches, such as the one presented by the Osteoarthritis Research Society International (OARSI) ${ }^{[18]}$. These two scores are extensively used. So, a biomarker based on image measures is an important task. It is common to associate the Joint Space Width (JSW) with OA stages ${ }^{[18,19]}$ this measurement helps to see the density of the cartilage and the loss of it, and the presence of osteophytes. The two most important scores are proved to be effective in the diagnosis and classification of the disease.

It is a challenge to correlate the features extracted with the help of scores from medical images and OA symptoms ${ }^{[20-22]}$. As we have detailed, this feature is a very important tool to diagnose the disease, but it's not clear yet, how it will help to explain some of the symptoms.

The objective of this work is to determine if a correlation exists between the features obtained from two of the most common radiological grading scales and the symptom that affects most the quality of life, pain. This represents a first step in developing a biomarker that predicts knee pain caused by OA.

In the work of Galván et al. is presented a search for the association between knee osteoarthritis and pain, developing a multivariate model based on elastic nets using semi-automatic measures with the purpose to predict future pain developed by knee osteoarthritis [23], and as in this work, it is proposed an initial biomarker developed by the same patients; however, here is presented a methodology based on genetic algorithms looking for the relation of the progression of pain caused by knee osteoarthritis.

The exploratory computational analysis of medical data can contribute to understanding better some diseases, prevent some disorders associated with early stages in some risk subjects. This can contribute to the improvement of health systems around the world. Computational statistics and Bioinformatics tools can be a powerful way to find some unexpected connec- 
tions between some subjects characteristics and symptoms of a certain disease ${ }^{[24-26]}$. This paper is organized as follows. After this introduction, our subject selection methodology is described in section II. In section III we present the statistical analysis of the data. Our results is presented in section IV. In section V all the discussion is presented. Finally, our conclusions and future work are presented in section VI and VII.

\section{METHODS}

OAI is a multi-center, longitudinal, prospective observational study of knee OA. The OAI will establish and maintain a natural history database for OA that will include clinical evaluation data, radiological ( $X$-ray and magnetic resonance) images, and a bio-specimen repository from 4796 men and women ages 45 to 79 enrolled between February 2004 and May 2006.

Datasets used in this work were: 'Central Assessment of Longitudinal Knee X-rays for Quantitative JSW' ver. 1.6, from which quantitative data were obtained; 'Central Reading of Knee X-rays for $K-L$ Grade and Individual Radiographic Features of Knee' ver. 1.6, from which semi-quantitative data were obtained; and 'Right knee symptom status', from which the predicted vari- able, pain, was obtained. This information was pre-analyzed by two different radiologist groups associated to the OAI. One group evaluated the images using the OARSI quantitative grading scale $[26,27]$ and the other the semi-quantitative $K-L$ grading scale ${ }^{[17,27]}$.

Only subjects with no radiological missing data were included in this study. The criteria for inclusion was not presenting pain as a symptom, not presenting a symptomatic status, and taking no pain medication at the baseline visit.

All control case should accomplish the inclusion criteria. From these, subjects having pain as a chronic symptom at some point in time, after their baseline and up to their 60 month visit were considered cases. The rest, the ones with no pain and no pain medicated from their baseline until their 60 month visit, were considered controls. Two different sets of subjects were selected according to the radiological data, one set for the quantitative analysis, and a second set for the semi-quantitative analysis. The demographic information of both sets is shown in Table 1. For each one of these analyses, three sets of data were generated, T0, T-1, T-2. In Figure 1 a scheme of subject selection is presented.

\section{TABLE 1. Demographic information.}

\begin{tabular}{|c|c|c|c|c|c|c|}
\hline & \multicolumn{2}{|c|}{ Quantitative analysis subjects } & \multicolumn{3}{c|}{ Semi-quantitative analysis subjects } \\
\hline & Cases & Controls & All & Cases & Controls & All \\
\hline Subjects (Females) & $65(38)$ & $98(55)$ & $163(93)$ & $63(35)$ & $60(26)$ & $123(61)$ \\
\hline Average height (S.D.) $[\mathrm{m}]$ & $1.69(.09)$ & $1.68(.1)$ & $1.68(.09)$ & $1.66(.23)$ & $1.69(.1)$ & $1.67(.18)$ \\
\hline Average BMI (S.D.) & $27.05(4.3)$ & $26.27(4)$ & $26.58(4.1)$ & $27.27(4.4)$ & $28.48(4.1)$ & $27.86(4.3)$ \\
\hline Average age (S.D.) & $62.69(9.6)$ & $61.80(10.1)$ & $62.15(9.9)$ & $65.02(9.6)$ & $66.72(8.7)$ & $65.85(9.2)$ \\
\hline Age range & $46-78$ & $45-79$ & $45-79$ & $46-78$ & $47-79$ & $46-79$ \\
\hline
\end{tabular}

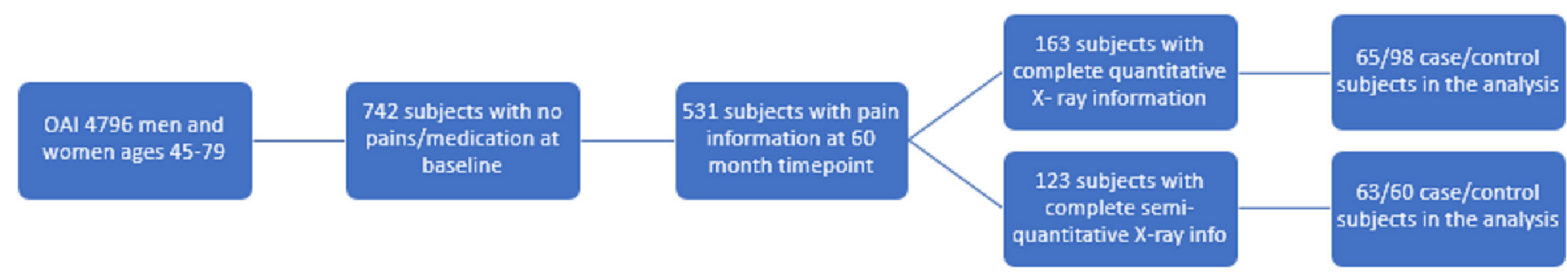


For To, using the information about the first appearance of pain as a symptom, data were analyzed using the 60 month pain information as the outcome variable, T- 1 analyzes the data a year before the pain appeared, T-2 analyzes the information two years before the pain appeared. The former included the radiological information measured at the timepoint the pain appeared as a symptom, and the latter, the information measured one year prior to the event. Seventeen quantitative and nineteen semi-quantitative features were measured in right knee radiographs, and their description is shown in Table 2. In order to avoid the bias caused by the different sizes of the knees between men and women (since men are generally taller), all image features from the quantitative datasets went through a height and gender adjustment using a linear regression as presented in equation 1 :

$$
J S W a d j=J S W-b 0-(\text { Height } * b 1)-(\text { Gender } * b 2)
$$

Where JSW adj represents the adjusted measurement, $J S W$ is the original measurement, and $b 0, b 1$ and $b 2$ are the coefficients obtained from the linear regression. The values assigned to the Gender variable were 0 for males and 1 for females. The data collected was $\mathrm{Z}$ normalized using the rank-based inverse normal transform ${ }^{[28]}$.

TABLE 2. Individual features and description.

\begin{tabular}{|c|c|c|c|}
\hline \multicolumn{2}{|c|}{ Quantitative Features } & \multicolumn{2}{c|}{ Semi Quantitative Features } \\
\hline Feature ID & Description & Feature ID & Description \\
\hline MCMJSW & Medial minimum JSW $(\mathrm{mm})$ & XROSFM & Osteophytes (OARSI grades 0-3) femur medial compartment \\
\hline JSW175 & Medial JSW at $\mathrm{x}=0.175[\mathrm{~mm}]$ & XRSCFM & Sclerosis (OARSI grades 0-3) femur medial compartment \\
\hline JSW200 & Medial JSW at $\mathrm{x}=0.200[\mathrm{~mm}]$ & XRCYFM & Cysts (Grades 0-1) femur medial compartment \\
\hline JSW250 & Medial JSW at $\mathrm{x}=0.250[\mathrm{~mm}]$ & XRJSM & Joint space narrowing (OARSI grades 0-3) medial compartment \\
\hline JSW300 & Medial JSW at $\mathrm{x}=0.300[\mathrm{~mm}]$ & XRCHM & Chondrocalcinosis (Grades 0-1) medial compartment \\
\hline JSW225 & Medial JSW at $\mathrm{x}=0.225[\mathrm{~mm}]$ & XROSTM & Osteophytes (OARSI grades 0-3) tibia medial compartment \\
\hline JSW150 & Medial JSW at $\mathrm{x}=0.150[\mathrm{~mm}]$ & XRSCTM & Sclerosis (oarsi grades 0-3) tibia medial compartment \\
\hline JSW275 & Medial JSW at $\mathrm{x}=0.275[\mathrm{~mm}]$ & XRCYTM & Cysts (Grades 0-1) tibia medial compartment \\
\hline LJSW850 & Lateral JSW at $\mathrm{x}=0.850[\mathrm{~mm}]$ & XRATTM & Attrition (OARSI grades 0-3) tibia medial compartment \\
\hline LJSW900 & Lateral JSW at $\mathrm{x}=0.900[\mathrm{~mm}]$ & XRKL & Kellgren and Lawrence (grades 0-4) \\
\hline LJSW700 & Lateral JSW at $\mathrm{x}=0.700[\mathrm{~mm}]$ & XROSFL & Osteophytes (OARSI grades 0-3) femur lateral compartment \\
\hline LJSW825 & Lateral JSW at $\mathrm{x}=0.825[\mathrm{~mm}]$ & XRSCFL & Sclerosis (OARSI grades 0-3) femur lateral compartment \\
\hline LJSW750 & Lateral JSW at $\mathrm{x}=0.750[\mathrm{~mm}]$ & XRCYFL & Cysts (Grades 0-1) femur lateral compartment \\
\hline LJSW875 & Lateral JSW at $\mathrm{x}=0.875[\mathrm{~mm}]$ & XRJSL & Joint space narrowing (OARSI grades 0-3) lateral compartment \\
\hline LJSW725 & Lateral JSW at $\mathrm{x}=0.725[\mathrm{~mm}]$ & XRCHL & Chondrocalcinosis $($ Grades 0-1) lateral compartment \\
\hline LJSW800 & Lateral JSW at $\mathrm{x}=0.800[\mathrm{~mm}]$ & XROSTL & Osteophytes (OARSI grades 0-3) tibia lateral compartment \\
\hline LJSW775 & Lateral JSW at $\mathrm{x}=0.775[\mathrm{~mm}]$ & XRSCTL & Sclerosis (OARSI grades 0-3)tibia lateral compartment \\
\hline & & XRCYTL & Cysts (Grades 0-1) tibia lateral compartment \\
\hline & & XRATTL & Attrition (OARSI grades 0-3) tibia lateral compartment \\
\hline
\end{tabular}

\section{STATISTICAL ANALYSIS}

After data transformations and normalizations, six univariate searches were performed, To, T-1, and T-2 in both quantitative and semi-quantitative scores. A logistic regression was used as a cost function in the univariate analysis, 60 month pain symptom was used as the outcome variable (0 indicates no pain, 1 indicates pain presence). After performing the logistic regression $P$-values and the area under the Receiver Operating Characteristic curve (AUC) was calculated on each feature.
After the univariate analysis, the multivariate searches were then performed for each score, using the To, T-1 and the T-2 data. For all searches, the 60 month visit pain information was used as the outcome. These searches were performed using Galgo ${ }^{\text {[29] }}$, a multivariate feature selection strategy based on genetic algorithms. The algorithm was set to return 600 predictive logistic regression models, with 5 features each. Each one of these models evolved throughout 200 generations, replicating, recombining and mutating from a set of mod- 
els with random features, optimizing for its accuracy, obtained using a 3 - fold cross validation with a 2/3-1/3 train-test proportion. Features were then ranked according to their frequency in the 600 models, and using such rank, a Forward Selection strategy was carried out, prompting a new predictive model. Finally, the size of this model was reduced by using a robust gene Backward feature elimination algorithm, in which fea-

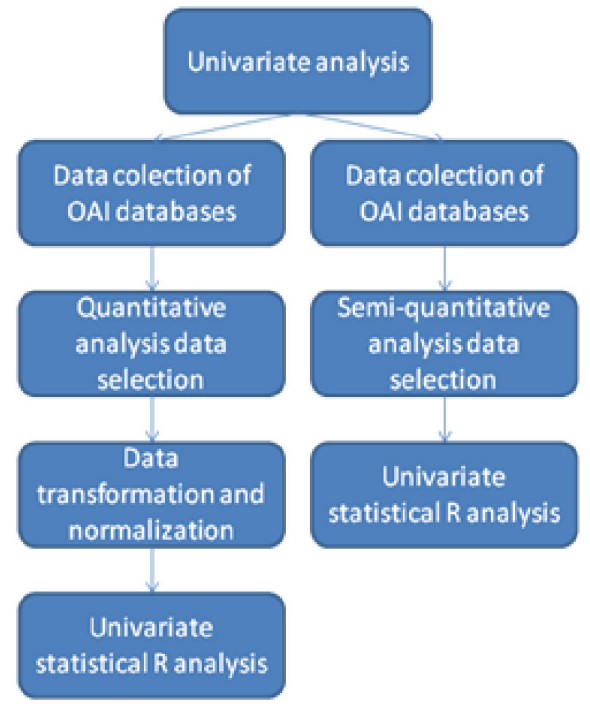

\section{EXPERIMENTS AND RESULTS}

The univariate analysis in quantitative data showed no statistical association between image features and future pain, in Table 3 the statistical information is presented. In semi quantitative data, the XROSFM is presented a significant $P$-Value, in Table 4 the statistical information about the analysis presented.

In multivariate analysis, for quantitative data: To information, the final model was a three feature model with an AUC of 0.6516, T-1 information the final model was a two feature model with an AUC of 0.6174, T-2 information the final model was a four feature model with an AUC of 0.6737. tures were removed if their contribution to the accuracy of the model, measured using the same cross-validation strategy, was negligible. AUC and Odd ratios were measured in the final model obtained in each of the 6 searches. All statistical analysis was done using R software. $\mathrm{R}$ is a free software environment for statistical computing and graphics ${ }^{[30]}$. In Figure 2 a scheme of the statistical analysis is presented.

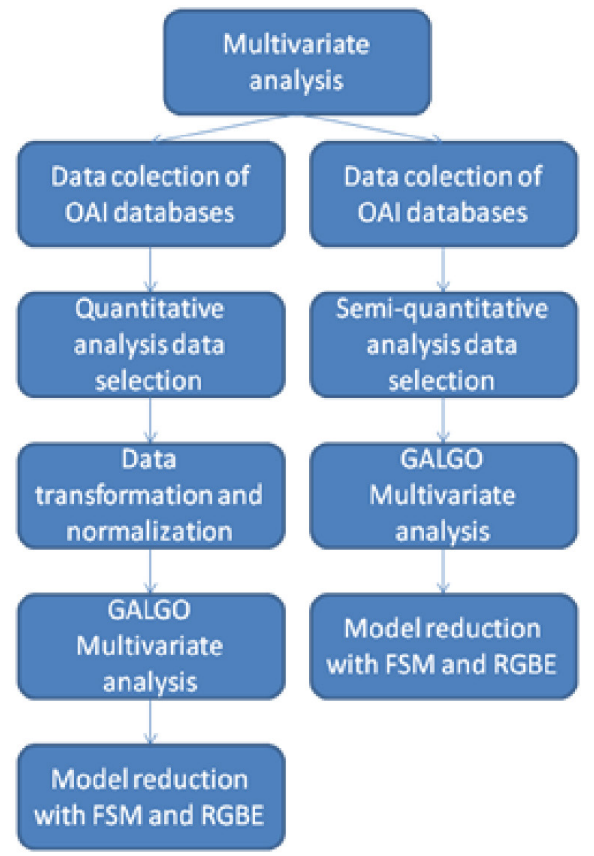

with ESM and RGBE

FIGURE 2. Data analysis scheme. model was a four variable model with an AUC of 0.6865 , T-1 information the final model was a two feature model with an AUC of 0.6486, T-2 information the final model was a two feature model with an AUC of 0.6406. In Table 5 the statistical information of 6 models is presented. In Figure $3 \mathrm{a}$ ) and $3 \mathrm{~b}$ ) the ROC curve of the models are presented. 
TABLE 3. Univariate quantitative features statistical information.

\begin{tabular}{|c|c|c|c|c|c|c|}
\hline & \multicolumn{2}{|c|}{ T-0 } & \multicolumn{2}{c|}{ T-1 } & \multicolumn{2}{c|}{ T-2 } \\
\hline Feature & P & AUC & P & AUC & P & AUC \\
\hline MCMJSW & 0.253 & 0.458 & 0.989 & 0.504 & 0.253 & 0.458 \\
\hline JSW175 & 0.196 & 0.545 & 0.615 & 0.487 & 0.196 & 0.545 \\
\hline JSW200 & 0.231 & 0.539 & 0.541 & 0.514 & 0.231 & 0.539 \\
\hline JSW250 & 0.057 & 0.571 & 0.543 & 0.523 & 0.057 & 0.571 \\
\hline JSW300 & $0.028^{*}$ & 0.584 & 0.185 & 0.553 & 0.028 & 0.584 \\
\hline JSW225 & 0.167 & 0.55 & 0.548 & 0.517 & 0.167 & 0.55 \\
\hline JSW150 & 0.21 & 0.541 & 0.686 & 0.508 & 0.21 & 0.541 \\
\hline JSW275 & 0.022 & 0.59 & 0.317 & 0.54 & $0.022^{*}$ & 0.59 \\
\hline LJSW850 & 0.251 & 0.575 & 0.355 & 0.567 & 0.251 & 0.575 \\
\hline LJSW900 & 0.243 & 0.575 & 0.231 & 0.579 & 0.243 & 0.575 \\
\hline LJSW700 & 0.161 & 0.567 & 0.539 & 0.551 & 0.161 & 0.567 \\
\hline LJSW825 & 0.221 & 0.574 & 0.372 & 0.566 & 0.221 & 0.574 \\
\hline LJSW750 & 0.196 & 0.577 & 0.453 & 0.557 & 0.196 & 0.577 \\
\hline LJSW875 & 0.291 & 0.573 & 0.296 & 0.574 & 0.291 & 0.573 \\
\hline LJSW725 & 0.202 & 0.566 & 0.492 & 0.544 & 0.063 & 0.618 \\
\hline LJSW775 & 0.196 & 0.573 & 0.329 & 0.567 & 0.196 & 0.573 \\
\hline LJSW800 & 0.21 & 0.575 & 0.307 & 0.573 & 0.21 & 0.575 \\
\hline
\end{tabular}

a)
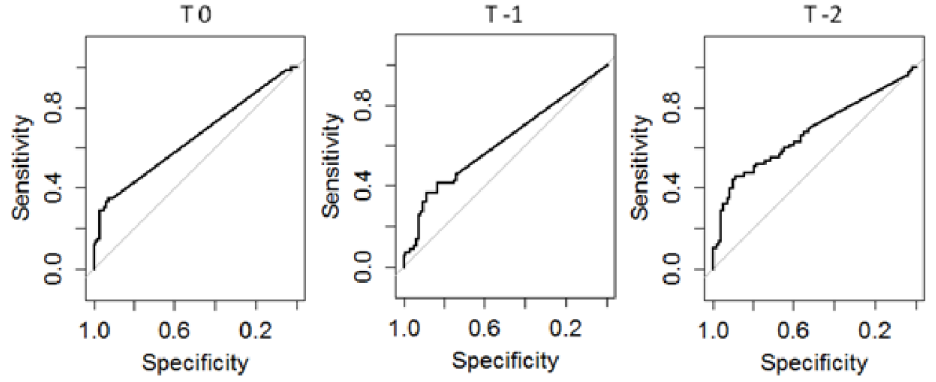

b)
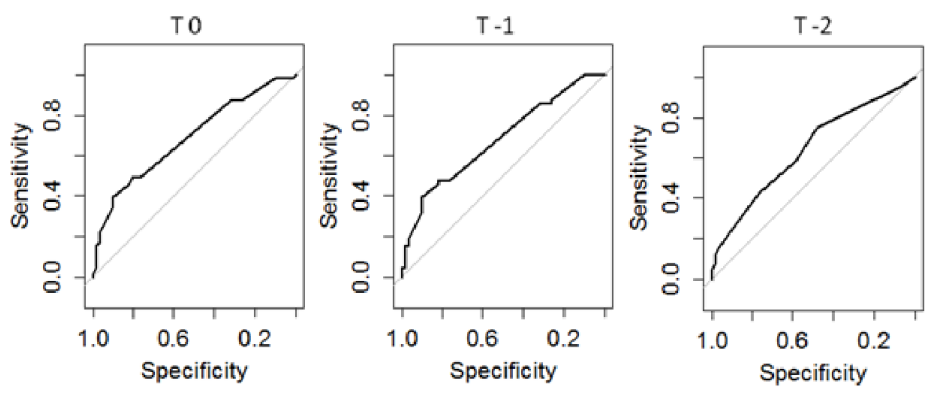

FIGURE 3. ROC Curves; a) Quantitative predictive models, b) Semi-quantitative predictive models. 


\section{V.DISCUSSION}

Unlike other cross-sectional studies ${ }^{[1,14,20]}$. This study take into account the time of incidence of chronic pain in the right knee as starting point. This with the intention to diminish the bias due to the difference in arrival of symptoms in patients included in the experiment.

We have produced a better OA prediction and diagnosis using statistical and computational models. It is evident from results that the use of multivariate models increases the predictive power of measurements obtained by knee $X$-rays.
Based on the results presented in Table 3 and Table 4, it is evident that variables associated with cartilage loss do not have a predictive capability by themselves.

Variables related with measurements based on scores do not show a tendency. Instead of that, they show a statistical significance individually. These variables are related to early changes in bone structure, such as osteophytes ${ }^{[31]}$. Moreover, the results presented in Table 5 show that multivariate analysis and variables based on semi quantitative measurements, could be used for a possible prediction and diagnosis.

TABLE 4. Univariate semi-quantitative features statistical information.

\begin{tabular}{|c|c|c|c|c|c|c|}
\hline & \multicolumn{2}{|c|}{ T-0 } & \multicolumn{2}{c|}{ T-1 } & \multicolumn{2}{c|}{ T-2 } \\
\hline Feature & $\mathrm{P}$ & AUC & P & AUC & P & AUC \\
\hline XROSFM & $0.006^{*}$ & 0.625 & $0.006^{*}$ & 0.619 & $0.011^{*}$ & 0.609 \\
\hline XRSCFM & 0.22 & 0.534 & 0.276 & 0.526 & 0.398 & 0.523 \\
\hline XRCYFM & 0.987 & 0.508 & 0.987 & 0.508 & 0.987 & 0.508 \\
\hline XRJSM & 0.722 & 0.501 & 0.978 & 0.492 & 0.687 & 0.527 \\
\hline XRCHM & 0.988 & 0.516 & 0.99 & 0.524 & 0.988 & 0.516 \\
\hline XROSTM & 0.779 & 0.525 & 0.682 & 0.532 & 0.782 & 0.528 \\
\hline XRSCTM & 0.778 & 0.5 & 0.88 & 0.498 & 0.905 & 0.516 \\
\hline XRCYTM & 0.96 & 0.501 & 0.96 & 0.501 & 0.96 & 0.501 \\
\hline XRATTM & 0.787 & 0.5 & 0.787 & 0.5 & 0.787 & 0.5 \\
\hline XRKL & 0.071 & 0.583 & 0.394 & 0.534 & 0.78 & 0.508 \\
\hline XROSFL & 0.023 & 0.595 & 0.079 & 0.562 & 0.048 & 0.572 \\
\hline XRSCFL & 0.231 & 0.516 & 0.548 & 0.507 & 0.691 & 0.499 \\
\hline XRCYFL & 0.987 & 0.508 & 0.987 & 0.508 & 0.987 & 0.508 \\
\hline XRJSL & 0.226 & 0.531 & 0.622 & 0.514 & 0.616 & 0.507 \\
\hline XRCHL & 0.988 & 0.516 & 0.988 & 0.516 & 0.988 & 0.516 \\
\hline XROSTL & 0.054 & 0.574 & 0.179 & 0.541 & 0.196 & 0.533 \\
\hline XRSCTL & 0.181 & 0.531 & 0.466 & 0.515 & 0.566 & 0.515 \\
\hline XRCYTL & 0.221 & 0.523 & 0.594 & 0.508 & 0.594 & 0.508 \\
\hline XRATTL & 0.988 & 0.516 & 0.988 & 0.516 & 0.988 & 0.516 \\
\hline
\end{tabular}

According to our study, early appearance of cartilage loss in medial knee, coupled with the early onset of changes in bone structure (osteophytes) may be associated with future chronic pain in the right knee ${ }^{[32,33]}$. The weaknesses of this study are given in the number of subjects, due to the selection criteria, many of the subjects had to be discarded. On the other hand, maintaining control subjects makes our models more robust. Since similar works do not include such controls. The results are relevant and consistent with expectations from the clinical point of view. We can consider adding other risk factors in order to diagnosis or timely forecast $\mathrm{OA}$. 
TABLE 5. Multivariate prediction models statistical information.

\begin{tabular}{|c|c|c|c|c|c|c|}
\hline \multicolumn{2}{|l|}{ Model } & Feature & Odd & $\mathrm{P}$-value & CI & $0 \%$ \\
\hline \multirow{9}{*}{ Quantitative } & \multirow{3}{*}{ T 0} & JSW200 & 6.194 & 0.059 & 1.078 & 53.227 \\
\hline & & JSW225 & 0.04 & 0.01 & 0.002 & 0.366 \\
\hline & & JSW275 & 12.029 & 0.001 & 3.229 & 63.611 \\
\hline & \multirow{2}{*}{$\mathrm{T}-1$} & JSW300 & 1.756 & 0.07 & 0.984 & 3.352 \\
\hline & & LJSW875 & 2.031 & 0.035 & 1.061 & 4.03 \\
\hline & \multirow{4}{*}{$\mathrm{T}-2$} & JSW175 & 0.354 & 0.096 & 0.101 & 1.194 \\
\hline & & JSW150 & 2.17 & 0.213 & 0.642 & 7.587 \\
\hline & & JSW250 & 0.232 & 0.107 & 0.032 & 1.232 \\
\hline & & JSW275 & 12.672 & 0.003 & 2.645 & 84.299 \\
\hline \multirow{10}{*}{ Semi-quantitative } & \multirow{4}{*}{ Т 0} & XRSCTM & 0.201 & 0.073 & 0.024 & 0.957 \\
\hline & & XRJSM & 0.655 & 0.281 & 0.298 & 1.405 \\
\hline & & XRSCFM & 6.818 & 0.053 & 1.162 & 64.729 \\
\hline & & XROSFM & 2.372 & 0.006 & 1.338 & 4.61 \\
\hline & \multirow{4}{*}{$\mathrm{T}-1$} & XROSFM & 2.726 & 0.002 & 1.522 & 5.369 \\
\hline & & XRSCFM & 7.874 & 0.031 & 1.426 & 64.665 \\
\hline & & XRJSM & 0.584 & 0.183 & 0.259 & 1.276 \\
\hline & & XRSCTM & 0.169 & 0.183 & 0.023 & 0.805 \\
\hline & \multirow{2}{*}{$\mathrm{T}-2$} & XROSFM & 2.313 & 0.006 & 1.32 & 4.449 \\
\hline & & XRKL & 0.771 & 0.242 & 0.494 & 1.189 \\
\hline
\end{tabular}

From the computational point of view, the use of stochastic methods such as genetic algorithms, allow us to explore a large amount of information and be able to build robust and small enough models in order to classify the characteristics of a disease. The use of these tools is growing in medical science worldwide, and use of computing power, and optimization algorithms are one of the options for the study of chronic degenerative diseases such as the $\mathrm{OA}^{[34]}$.

\section{CONCLUSIONS}

The results suggest that some early radiological features can be associated with OA symptoms. It is possible to achieve future pain prediction with multivariate models based on $X$-ray features. The association of future pain with $X$-ray features can be used to develop a prevention strategy for chronic pain. The public health systems could take advantage of the use of a radiological biomarkers.
Besides that, computational analysis of data sets can be very helpful to develop image based biomarkers, due to its nature, this analysis can manage big data sets and perform millions of operations to correlate some features/situations of subjects with disease symptoms in order to have a better and faster diagnosis.

The present study shows a close relation between the $X$-ray based models obtained with the multivariate regression and the develop of clinical pain associated with the disease, which strongly suggest the feasibility of a biomarker based in those features.

This biomarker can be used to aid the radiologist in the process of diagnose the patient or as a second opinion. Also, these models can be used with common technology ( $X$-rays). So, it can be easily used in developing countries, in which access to high level health care systems is very restricted. 


\section{FUTURE WORK}

In future work, a relationship between the $X$-ray features and clinical data will be explored. Using different bioinformatics and medical statistics tools, a combination of clinical and radiological features can be searched to obtain a robust biomarker. Also, The use of image registration will be explored as a predictor of future knee pain. Since access to the high level health care system is very restricted. Then, using the new available information in OAI databases, a larger study will be explored, up to five years prior to pain incidence.

In the other hand, an exploration of left knee in combination with the right knee information can be useful to obtain a better predictor based on multivariate models. This option will be tackled with OAI databases and clinical information.

Finally, it's proposed a data recompilation from Mexican patients for future studies, looking for the comparison between the results obtained in this work and the results obtained with the information of the
Mexican phenotype, since the demography is a significant feature in the patients studies.

\section{ACKNOWLEDGEMENTS}

This work was partially supported by the Consejo Nacional de Ciencia y Tecnología (CONACYT), by Grant 16864 Ciencia Básica from CONACYT.

"The OAI is a public-private partnership comprised of five contracts (N01-AR-2-2258; No1-AR-2-2259; No1-AR-2-2260; N01-AR-2-2261; N01-AR-2-2262) funded by the National Institutes of Health, a branch of the Department of Health and Human Services, and conducted by the OAI Study Investigators. Private funding partners include Merck Research Laboratories; Novartis Pharmaceuticals Corporation, GlaxoSmithKline; and Pfizer, Inc. Private sector funding for the OAI is managed by the Foundation for the National Institutes of Health. This manuscript was prepared using an OAI public use data set and does not necessarily reflect the opinions or views of the OAI investigators, the $\mathrm{NIH}$, or the private funding partners." 


\section{REFERENCIAS}

[1] Neogi T, Felson D, Niu J, Nevitt M, Lewis CE, Aliabadi P, et al. Association between radiographic features of knee osteoarthritis and pain: results from two cohort studies. Bmj. 2009;339:b2844.

[2] Rosenzweig DH, Quinn TM, Haglund L. Low-frequency high-magnitude mechanical strain of articular chondrocytes activates p38 MAPK and induces phenotypic changes associated with osteoarthritis and pain. International journal of molecular sciences. 2014;15(8):14427-14441.

[3] Davis J, Eaton CB, Lo GH, Lu B, Price LL, McAlindon TE, et al. Knee symptoms among adults at risk for accelerated knee osteoarthritis: data from the Osteoarthritis Initiative. Clinical rheumatology. 2017;36(5):1083.

[4] White DK, Tudor-Locke C, Felson DT, Gross KD, Niu J, Nevitt M, et al. Do radiographic disease and pain account for why people with or at high risk of knee osteoarthritis do not meet physical activity guidelines? Arthritis \& Rheumatism. 2013;65(1):139-147.

[5] Neogi T. The epidemiology and impact of pain in osteoarthritis. Osteoarthritis and Cartilage. 2013;21(9):1145-1153.

[6] Colbert CJ, Almagor O, Chmiel JS, Song J, Dunlop D, Hayes KW, et al. Excess body weight and four-year function outcomes: Comparison of African Americans and whites in a prospective study of osteoarthritis. Arthritis care \& research. 2013;65(1):5-14.

[7] Riddle DL, Stratford PW. Body weight changes and corresponding changes in pain and function in persons with symptomatic knee osteoarthritis: a cohort study. Arthritis care \& research. 2013;65(1):15-22.

[8] Tanamas SK, Wluka AE, Davies-Tuck M, Wang Y, Strauss BJ, Proietto J, et al. Association of weight gain with incident knee pain, stiffness, and functional difficulties: a longitudinal study. Arthritis care \& research. 2013;65(1):34-43.

[9] Abhishek A, Doherty M. Mechanisms of the placebo response in pain in osteoarthritis. Osteoarthritis and Cartilage.

2013;21(9):1229-1235.

[10] van Oudenaarde K, Jobke B, Oostveen AC, Marijnissen AC, Wolterbeek R, Wesseling J, et al. Predictive value of MRI features for development of radiographic osteoarthritis in a cohort of participants with pre-radiographic knee osteoarthritis the CHECK study. Rheumatology. 2016;p. kew368.

[11] Guermazi A, Niu J, Hayashi D, Roemer FW, Englund M, Neogi T, et al. Prevalence of abnormalities in knees detected by MRI in adults without knee osteoarthritis: population based observational study (Framingham Osteoarthritis Study). Bmj. 2012;345:e5339.

[12] Wirth W, Duryea J, Le Graverand MPH, John MR, Nevitt M, Buck R, et al. Direct comparison of fixed flexion, radiography and MRI in knee osteoarthritis: responsiveness data from the Osteoarthritis Initiative. Osteoarthritis and Cartilage. 2013;21(1):117-125.

[13] Cotofana S, Wyman BT, Benichou O, Dreher D, Nevitt M, Gardiner $\mathrm{J}$, et al. Relationship between knee pain and the presence, location, size and phenotype of femorotibial denuded areas of subchondral bone as visualized by MRI. Osteoarthritis and Cartilage. 2013;21(9):1214-1222. [14] Haugen I, Slatkowsky-Christensen B, Bøyesen P, van der Heijde D, Kvien T. Cross-sectional and Cartilage. 2013;21(9):1214-1222.
[14] Haugen I, Slatkowsky-Christensen B, Bøyesen P, van der Heijde D, Kvien T. Cross-sectional and longitudinal associations between radiographic features and measures of pain and physical function in hand osteoarthritis. Osteoarthritis and Cartilage.

2013;21(9):1191-1198.

[15] Rahman MM, Kopec JA, Goldsmith CH, Anis AH, Cibere J. Validation of administrative osteoarthritis diagnosis using a clinical and radiological population-based cohort. International journal of rheumatology. 2016;2016.

[16] Boesen M, Ellegaard K, Henriksen M, Gudbergsen H, Hansen P, Bliddal H, et al. Osteoarthritis year in review 2016: imaging. Osteoarthritis and cartilage. 2016;.

[17] Kellgren J, Lawrence J. Atlas of standard radiographs: the epidemiology of chronic rheumatism. Vol. 2. Oxford: Blackwell. 1963;

[18] Blöcker K, Guermazi A, Wirth W, Benichou O, Kwoh CK, Hunter D, et al. Tibial coverage, meniscus position, size and damage in knees discordant for joint space narrowing-data from the Osteoarthritis Initiative. Osteoarthritis and cartilage. 2013;21(3):419-427.

[19] Attur M, Krasnokutsky-Samuels S, Samuels J, Abramson SB. Prognostic biomarkers in osteoarthritis. Current opinion in rheumatology. 2013;25(1):136.

[20] Kinds MB, Marijnissen AC, Bijlsma JW, Boers M, Lafeber FP, Welsing PM. Quantitative radiographic features of early knee osteoarthritis: development over 5 years and relationship with symptoms in the CHECK cohort. The Journal of rheumatology. 2013;40(1):58-65.

[21] Glass N, Torner J, Law LF, Wang K, Yang T, Nevitt M, et al. The relationship between quadriceps muscle weakness and worsening of knee pain in the MOST cohort: a 5-year longitudinal study. Osteoarthritis and Cartilage. 2013;21(9):1154-1159.

[22] Shimura Y, Kurosawa H, Sugawara Y, Tsuchiya M, Sawa M, Kaneko $\mathrm{H}$, et al. The factors associated with pain severity in patients with knee osteoarthritis vary according to the radiographic disease severity: a cross-sectional study. Osteoarthritis and Cartilage. 2013;21(9):1179-1184.

[23] Galván-Tejada JI, Celaya-Padilla JM, Treviño V, Tamez-Peña JG. Multivariate radiological-based models for the prediction of future knee pain: Data from the OAI. Computational and mathematical methods in medicine. 2015;2015.

[24] Galván-Tejada J, Martinez-Torteya A, Totterman S, Farber J, Treviño V, Tamez-Pena J. A wide association study of predictors of future knee pain: data from the osteoarthritis initiative. Osteoarthritis and Cartilage. 2012;20:S85.

[25] Martinez-Torteya A, Galván-Tejada J, Totterman S, Farber J, Treviño V, Tamez-Pena J. Can T2 relaxation be used to predict koos other symptoms?-data from the osteoarthritis initiative. Osteoarthritis and Cartilage. 2012;20:S208-S209.

[26] Torteya AM, Peña JGT, Alvarado VMT. Multivariate predictors of clinically relevant cognitive decay: A wide association study using available data from ADNI. Alzheimer's \& Dementia. 2012;8(4):P285-P286. 
[27] Felson DT, Nevitt MC, Yang M, Clancy M, Niu J, Torner JC, et al. A new approach yields high rates of radiographic progression in knee osteoarthritis. The Journal of rheumatology. 2008;35(10):20472054.

[28] Beasley TM, Erickson S, Allison DB. Rank-based inverse normal transformations are increasingly used, but are they merited? Behavior genetics. 2009;39(5):580-595.

[29] Trevino V, Falciani F. GALGO: an R package for multivariate variable selection using genetic algorithms. Bioinformatics. 2006;22(9):1154-1156.

[30] R Core Team. R: A Language and Environment for Statistical Computing. Vienna, Austria; 2014. Available from: http:// www.R-project.org/.

[31] Chu JG, Dai MW, Wang Y, Tian FM, Song HP, Xiao YP, et al. Strontium ranelate causes osteophytes overgrowth in a model of early phase osteoarthritis. BMC musculoskeletal disorders. 2017;18(1):78
[32] Zhu Z, Laslett L, Jin X, Han W, Antony B, Wang X, et al. Association between MRI-detected osteophytes and changes in knee structures and pain in older adults: a cohort study. Osteoarthritis and cartilage. 2017;.

[33] Serban O, Porojan M, Deac M, Cozma F, Solomon C, Lehghel M, et al. Pain in bilateral knee osteoarthritis-correlations between clinical examination, radiological, and ultrasonographical findings. Medical ultrasonography. 2016;18(3):318-325.

[34] Ashinsky BG, Bouhrara M, Coletta CE, Lehallier B, Urish KL, Lin PC, et al. Predicting early symptomatic osteoarthritis in the human knee using machine learning classification of magnetic resonance images from the osteoarthritis initiative. Journal of Orthopaedic Research. 2017; 